\title{
TECNOLOGIA DIGITAL E AGÊNCIA: RESSIGNIFICANDO A TAREFA DA ESCRITA ESCOLAR
}

\section{DIGITAL TECHNOLOGY AND AGENCY: RE-SIGNIFYING THE SCHOOL TASK OF WRITING}

\author{
Júlio Araújo* \\ Messias Dieb*
}

\begin{abstract}
RESUMO: Os conceitos de agência, letramentos e relação com o saber iluminam a análise das relações que estudantes de uma escola situada em zona periférica de Fortaleza têm construído com a tarefa da escrita envolvendo as tecnologias digitais. Os resultados mostram que, pelo exercício da escrita de tirinhas em ferramentas digitais, como a Pixton, esses sujeitos se movimentam no ambiente estruturante da escola e nele tentam obter suas conquistas, tanto pessoais como coletivas, auxiliados pelos recursos que tais tecnologias oferecem.
\end{abstract}

PALAVRAS-CHAVE: Escrita. Tecnologia digital. Agência. Letramentos. Relação com o saber.

\begin{abstract}
The notions of agency, literacy and relationship to knowledge aid the analysis of the relationships that students have constructed to the task of writing in schools of peripheral zones of the city of Fortaleza - Ceará - Brazil. The data show that, producing comic strips with the aid of digital technologies tools, as Pixton, they try to achieve success in their interactions in the structured environment of the school, both personally and collectively, aided by the resources that such technologies can offer.
\end{abstract}

KEYWORDS: Writing. Digital technology; Agency. Literacies. Relationship to the knowledge.

\footnotetext{
* Universidade Federal do Ceará (UFC), Fortaleza - CE. Pós-Doutor em Estudos Linguísticos pela UFMG. Professor no Programa de Pós-Graduação em Linguística, do Departamento de Letras Vernácula da UFC, onde coordena o grupo de pesquisa Hiperged. E-mail araujo@ufc.br; Site pessoal: http://www.julioaraujo.com

* Universidade Federal do Ceará (UFC), Fortaleza - CE. Doutor em Educação pela UFC. Professor no Programa de Pós-Graduação em Educação Brasileira, da Faculdade de Educação da UFC. E-mail dieb@ufc.br
} 


\section{INTRODUÇÃO}

De acordo com Monlevade (1997), a implantação de escolas no Brasil se deu muito lentamente a partir da chegada dos padres jesuítas, em 1549, quase cinquenta anos depois que o Rei de Portugal havia se apossado das terras brasileiras. Essa implantação abrangeu a fundação de colégios, especialmente voltados para a instrução dos filhos dos brancos que serviam à corte portuguesa, e de escolas primárias, que tinham o objetivo de converter os índios ao cristianismo católico. Obviamente, nenhuma dessas duas modalidades de escola foi acessível aos negros, entre os séculos XVI e XIX, devido a sua condição de escravos.

Em 1758, para que pudesse pagar uma grande dívida com os bancos ingleses, e ao mesmo tempo diminuir o prestígio dos jesuítas, o qual se tornara crescente em várias províncias brasileiras, o Primeiro Ministro de Portugal, Marquês de Pombal, expulsou os padres da sede da Corte portuguesa e de todas as suas colônias, confiscando toda a riqueza por eles acumulada. A partir de então, até 1772, ano em que foi criado o esquema das Aulas Régias, não tivemos mais nada de educação pública no Brasil. Esse esquema funcionou com base na iniciativa de alguns poucos cidadãos alfabetizados que, se quisessem instruir os demais, deveriam conseguir um espaço disponível para o ensino e, após receber autorização do Rei, dar suas aulas em troca de um mísero salário conhecido como "subsídio literário", o qual era "cobrado dos açougues e destilarias de cachaça, no litoral e no interior da Colônia" (MONLEVADE, 1997, p.24).

De um modo sintético, no percurso de concepção e construção da escola brasileira, esta sempre se configurou como uma instituição altamente elitista e seletiva, marcada principalmente pela cultura do "apadrinhamento" em relação ao seu acesso e pela exclusão das classes menos favorecidas da sociedade. Essas classes, devido ao escasso acesso aos bens culturais e às oportunidades de formação sistematizada, tornaram-se mais vulneráveis aos efeitos da violência urbana, das desigualdades sociais 
e econômicas, bem como à irracionalidade dos inescrupulosos projetos políticos que fomentam tudo isso. Só muito recentemente, por meio das determinações da atual Lei de Diretrizes e Bases da Educação Nacional - LDB, Lei n. ${ }^{\circ}$ 9.394/96 (BRASIL, 1996), que substituiu a Lei n. ${ }^{\circ}$ 5.692/71, e da criação de fundos especiais para o financiamento da educação brasileira, é que a escola, nas últimas três décadas, tem sido pensada e discutida com o intuito de garantir uma educação formal de qualidade para todos, universalizando especialmente os nove anos do ensino fundamental.

Devido a esse processo de universalização/democratização do ensino fundamental público, jovens com diferentes condições de escolaridade, geralmente oriundos de meios populares e populosos, onde a violência e a falta de oportunidades também são bastante comuns, têm adentrado os espaços escolares. Ao considerarmos os fatos históricos, acima, acerca do descaso na educação sistematizada no Brasil, constatamos que muitos desses jovens são filhos de pais que nunca, ou raramente, frequentaram a escola. Trata-se, como afirma Charlot (2012), de uma nova população de alunos que, ao entrarem em qualquer segmento do sistema escolar, e até mesmo universitário, trazem consigo novas contradições para dentro desse sistema. Portanto, com a democratização da escola, é inevitável o confronto entre diferentes coletividades (agências) no âmbito dessa instituição, estruturada com suas respectivas alteridades e percepções de mundo.

Como seres históricos e sociais, os indivíduos humanos (agentes, atores e também sujeitos) são sempre insuflados a interagir nas situações que experimentam coletivamente e, para isso, fazem uso necessariamente de tecnologias disponíveis em sua época e na macroestrutura social da qual são partícipes, ainda que o acesso a essas tecnologias seja, de certo modo, restrito. Atualmente, com o advento das tecnologias digitais, a escola, em sua incumbência de universalizar/democratizar o acesso ao saber, tem buscado utilizar, no processo ensino-aprendizagem, os modernos recursos tecnológicos de informática, sendo, talvez, esta a única oportunidade de acesso a tais recursos para uma boa parte do público que é atendido por essa instituição, com ênfase nas camadas menos abastadas da sociedade. Em razão dessa constatável realidade, e em especial nos estados da região nordeste do Brasil, nos perguntamos: a partir do exercício de sua agência no espaço escolar, que significado a população estudantil, em zonas periféricas da cidade de Fortaleza - Ceará - Brasil, por exemplo, tem atribuído à tarefa da escrita quando esta envolve as tecnologias digitais, em especial o computador conectado à internet? Em busca de respostas para esta questão, nos guiaremos pela suposição de que, em um país como o Brasil onde, ainda hoje, apenas na escola algumas crianças encontram a chance de ter contato com a leitura e a escrita, em geral por meio do livro didático, a oportunidade de utilizar recursos com tecnologia digital nesse ambiente tende a produzir forte mobilização em tais sujeitos para a aprendizagem de novas práticas de letramento e, em especial, para a manifestação de sua agência.

Com base nos aspectos apresentados acima, discutiremos, neste artigo, a relação que estudantes de escola pública, em zonas periféricas da cidade de Fortaleza, têm construído com a tarefa escolar da escrita envolvendo as tecnologias digitais, a fim de compreender como eles se movimentam no ambiente estruturante da escola e nele tentam obter suas conquistas, tanto pessoais como coletivas, auxiliados pelos recursos que tais tecnologias oferecem. Analisaremos essa relação guiados também por outra suposição, a de que os citados estudantes balizam sua relação com a escrita, fazendo uso de ferramentas digitais, a partir das possibilidades que tais recursos apresentam para afiançar, de modo prudente, a expressão de julgamentos práticos e normativos que eles 
formulam acerca de sua condição social e da própria instituição escolar (com seus preceitos e promessas). Para dar maior clareza aos complexos elementos dessa suposição, apresentaremos, na sequência, o contexto em que a pesquisa foi realizada e, posteriormente, as noções teóricas de agência e de relação com o saber, com as quais buscaremos dialogar com os novos estudos de letramento.

\section{CONTEXTO E DESENVOLVIMENTO DA PESQUISA}

A reflexão empreendida, neste texto, nasce de uma pesquisa que realizamos a partir de um programa de extensão chamado Amplinks ${ }^{1}$ (ampliando links), o qual se insere no grupo de pesquisa Hiperged, do Programa de Pós-Graduação em Linguística (PPGL) na Universidade Federal do Ceará (UFC). Atualmente, o programa Amplinks atende a quatro (4) escolas públicas da cidade de Fortaleza e duas (2) de cidades da região metropolitana. Por meio desse programa, assessoramos as escolas na criação de condições didáticas através das quais seja possível trazer para o espaço educativo concretas situações de escrita em ambientes digitais. Nelas, buscamos proporcionar oportunidades para que o estudante sinta desejo e necessidade de interagir ao perceber que são ferramentas sociais portadoras de sentidos, de propósitos comunicativos, e que se traduzem em fontes de informações variadas e de saberes a serem construídos e mobilizados por eles. Por meio desse programa, realizamos diversas Oficinas de Letramento Digital (OLDs) direcionadas a crianças e adolescentes que estudam em escolas públicas de áreas carentes da cidade de Fortaleza e região Metropolitana.

Essas oficinas têm entre os seus objetivos promover práticas de letramento digital por meio da produção de histórias em quadrinhos (HQ), e/ou tirinhas, com o uso de várias ferramentas digitais, entre elas a Pixton (http://www.pixton.com/br/) com a qual ilustraremos a argumentação nesse trabalho. A Pixton é um site que permite criar HQs e/ou tirinhas com a utilização de diversos recursos, bastando apenas que os alunos cadastrem-se com suas contas de e-mail ou, caso não as tenham, utilizem o e-mail do professor. O site oferece acesso gratuito a um pacote básico de imagens, com vários personagens e objetos cenográficos para que sejam montadas as histórias, as quais ficam disponíveis na rede para publicação e leitura posteriores.

As escolas em que as OLDs são realizadas possuem, de um modo geral, um laboratório de informática, o qual é utilizado quase que unicamente para atividades de pesquisa de informações em sites de busca. Isto se justifica porque falta, por parte do poder público, uma política mais efetiva de formação dos professores em relação aos usos desses laboratórios. Os professores dessas escolas, geralmente de bairros populares, relatam que os estudantes possuem algumas dificuldades em relação aos usos escritos da língua porque o contato deles com materiais escritos é bastante restrito (DIEB, 2013). No entanto, devido ao fato de os alunos já terem construído certa familiaridade com o uso de computadores conectados à internet, através das lan houses, essas dificuldades em relação aos usos escritos da língua têm, a priori, diminuído. A maior preocupação dos docentes, atualmente, reside no fato de eles estarem cada vez mais habituados às abreviações e às elipses vocálicas típicas da linguagem escrita em determinados ambientes digitais, como é o caso das redes sociais, por exemplo (ARAÚJO, 2013).

\footnotetext{
${ }^{1}$ Para mais detalhes acerca do Amplinks, acessar o site http://www.hiperged.ufc.br/\#!extensao/c18yd
} 
Nesse contexto, apresentaremos, para este artigo, dados oriundos das OLDs ministradas por uma professora colaboradora do programa Amplinks que atua em uma determinada escola de educação infantil e de ensino fundamental, situada em um bairro periférico de Fortaleza. A referida escola foi fundada no ano 2000 e teve sua construção a partir de uma luta aguerrida da associação de moradores desse bairro que, antes desse período, não possuía nenhuma escola. Após concluída a sua construção, a instituição recebeu o nome de um jovem da comunidade que batalhava pelo crescimento de seu bairro, mas que faleceu, vítima de um câncer, aos dezoito anos de idade, antes mesmo que a escola fosse inaugurada. Escolhemos essa escola porque, além de termos sido aceitos sem restrições para o desenvolvimento das atividades relativas ao Amplinks, ela conta com um bom laboratório de informática, que não era utilizado regularmente pelos professores nem pelos alunos, apesar de dispor de conexão à internet $W i-F i$ e banda larga, o que nos deu condições técnicas necessárias para o trabalho com as oficinas de letramentos digitais.

O tema proposto para composição das tirinhas foi o cotidiano dos alunos e da comunidade na qual a escola se insere. Optamos por deixar um tema livre e aberto como estratégia para garantirmos a adesão dos estudantes às oficinas das quais participaram 28 alunos do ensino fundamental II. Esses estudantes se engajaram com entusiasmo no projeto, produzindo historinhas sui generis cujo conteúdo apontava para um cotidiano violento e uma realidade bastante triste. Após lermos as tirinhas e percebermos seu conteúdo, resolvemos entrevistar os autores dos quadrinhos a fim de compreendermos os significados em torno da produção desses textos. O critério para participar da entrevista era a simples aceitação ao nosso convite e, assim, três (3) autores das tirinhas se dispuseram a conversar conosco, permitindo que a conversa fosse gravada em áudio. Para tornar o ambiente da entrevista menos formal, usamos o gravador de voz do smartphone da própria professora. Após a entrevista, usamos o software Speechoo ${ }^{2}$ para nos assessorar na tarefa de transcrição das entrevistas que, após transcritas e revisadas por nós, foram mostradas aos pais dos estudantes que, gentilmente, permitiram o uso desse material e das tirinhas produzidas por seus filhos como corpus para as análises que apresentaremos mais adiante.

Tanto as tirinhas quanto os trechos da entrevista representam, pois, um material de estudo interessante para compreendermos a agência dos alunos diante da estrutura escolar da qual participam e, para além disso, avaliarmos as possibilidades e limites relativos à utilização do laboratório de informática na escola.

\section{AS NOÇõES DE AGÊNCIA E DE RELAÇÃO COM O SABER NOS NOVOS ESTUDOS DO LETRAMENTO}

Ao pensarmos sobre o binômio agência-estrutura no campo das ciências sociais é preciso que afirmemos nossa "filiação" teórico-conceitual acerca do tema e da referida noção, uma vez que, a partir dela, buscaremos estabelecer um diálogo entre aspectos relevantes concernentes ao exercício subjetivo da agência e alguns pontos específicos da teoria da relação com o saber, de Bernard Charlot (1997), perpassados pela ideia dos novos letramentos engendrada nos estudos de Street $(1984$; 1988) e Barton e Hamilton

\footnotetext{
${ }^{2}$ Este software foi programado pelo grupo Fala Brasil, da Universidade Federal do Pará, para o reconhecimento de voz e transcrição para o português brasileiro. Cf. http://www.laps.ufpa.br/falabrasil/speechoo.php. Acesso em 21 de novembro de 2012.
} 
(2000). É, portanto, fruto desse diálogo o nosso entendimento de que todo indivíduo, para além de agente e ator, é também um sujeito e, por isso, possui a capacidade de mobilizar recursos materiais (tecnológicos) e humanos (psíquicos), incluindo a si próprio como um desses recursos, a fim de apropriar-se do mundo em sua volta, por meio da linguagem, e de pôr em questão as estruturas, transformando os significados institucionalizados do que se encontra estabelecido.

Para melhor delinear o contorno dessas afirmações, compreenderemos estrutura como um sistema hierarquizado de poder e de privilégios, o qual é determinado tanto pelas relações materiais e/ou econômicas (salário, renda) como pelas relações simbólicas (status) e/ou culturais (escolarização) entre os indivíduos. Assim sendo, faremos referência à noção de agência na perspectiva de Emirbayer e Mische (1998, p.971) para quem se trata da "capacidade dos atores para formular criticamente suas próprias respostas a situações problemáticas". Nesse percurso de elaboração responsiva dos indivíduos humanos, a agência se configura, pois, como "um processo de engajamento social permeado de temporalidade" (idem, p.963 - tradução nossa), uma vez que tais indivíduos estão continuamente reconstruindo sua visão do passado, em resposta a mudanças no contexto em que se encontram, no qual tentam entender a dependência provocada pelas situações que emergem do presente, ao mesmo tempo em que se utilizam deste entendimento para controlar e modelar suas respostas em um futuro que lhes parece previsto.

Nesse movimento, contornado de temporalidades, os agentes (sujeitos e atores sociais) praticam um fluxo contínuo de condutas que vão, quase sempre, ao encontro de sua posição e de sua condição no espaço social. Por este motivo é que Archer (2003, p.261) afirma que "agentes são definidos como coletividades que partilham das mesmas oportunidades de vida" e, "por causa disso, [...] todo mundo é necessariamente um Agente, desde que ser um Agente implique simplesmente ocupar uma posição na distribuição dos escassos recursos sociais". Assim como nós, Archer também admite que, com o tempo, os agentes se tornam atores e "adquirem suas identidades sociais a partir do modo como eles personificam os papeis que escolhem para ocupar". Com efeito, o que podemos inferir dessas afirmações é que os agentes são também atores e sujeitos, pois impregnam de intenções as estruturas, haja vista estas funcionarem como "sistemas" sociais e culturais submetidos sempre a desejos e projetos humanos (ORTNER, 1996). Em acréscimo, defendemos que a personificação dos papeis escolhidos pelos indivíduos está intrinsecamente atrelada ao significado que eles atribuem a esse papel, ou seja, tem a ver com a postura que adotam no espaço social, já que a sua posição social objetiva (concreta) pode sofrer alterações e ser substituída por uma posição subjetiva (imaginária), redesenhada a partir do que move subjetivamente esses indivíduos em relação ao mundo e aos outros com quem partilham o mundo (CHARLOT, 1997).

A partir dessa visão de agência, defenderemos que o agente, por ser também ator e sujeito, desenvolve sua capacidade de movimentar-se e de comunicar-se dentro da estrutura de um campo, no qual ele se encontra momentaneamente situado, elaborando seus modos de ser e de estar nesse espaço de relações, podendo sempre, a partir de suas intenções e vontades, tentar a reconfiguração das estruturas de pensamento e de ação por ele recebidas para elaborar estratégias de ações futuras. Consoante Bourdieu e Wacquant (1992, p.97 - tradução nossa),

um campo pode ser definido como uma rede, ou uma configuração de relações objetivas entre as posições. Estas posições são definidas 
objetivamente na sua existência e nas determinações que elas impõem aos seus ocupantes, agentes ou instituições, por sua situação (situs) atual e potencial na estrutura de distribuição das diferentes espécies de poder (ou de capital) cuja posse comanda o acesso aos benefícios específicos que estão em jogo no campo, assim como por suas relações objetivas com as outras posições (dominação, subordinação, homologia etc.).

Sendo, pois, o sistema escolar de educação um bom exemplo para essa definição de campo, podemos afirmar que nele existem padrões estabelecidos de comportamento e uma certa normatividade nas relações. Os agentes, mediados por esses padrões e normas, estão sempre em disputa para a manutenção das identidades e das interações que ali se tornaram típicas, a exemplo do papel e do lugar social ocupados por alunos e professores. Esses indivíduos construíram, ao longo de suas vidas, uma representação acerca desses papéis sociais, a qual dificilmente será confrontada ou até mesmo reformulada sem que haja uma mudança radical no significado das relações que orientam e configuram o campo escolar.

Não obstante as forças hierárquicas que impõem determinações aos ocupantes de um determinado campo, como exposto na definição de Bourdieu e Wacquant (1992), sua estrutura pode sofrer consequências transformadoras ao longo do tempo. Em razão dessa possibilidade, podemos perfeitamente constatar que o surgimento das atuais tecnologias digitais e os letramentos que seus usos possibilitam emergir podem dar impulso a significativas transformações nas lógicas do sistema escolar, utilizado aqui como um exemplo de campo. Nesse sentido, os new literacy studies (NLS) (GEE, 1990; STREET, 1995) e a abordagem da relação com o saber (CHARLOT, 1997) oferecem uma relevante contribuição para discutirmos transformações nesse campo, a partir das disputas entre os agentes e as instituições que o constituem, visto que essas duas perspectivas conferem capacidade aos indivíduos para alterar realidades. Isso se justifica porque, as disputas, todas elas mediadas pelo uso da linguagem, estão sempre orientadas por regularidades e por normas que são partilhadas socialmente, mas que, em algumas circunstâncias, podem ser ultrapassadas pelos próprios agentes desse campo ao exercerem sua condição de sujeitos.

No que concerne à compreensão acerca do que significariam os NLS, Street (2003, p.77) assinala que a referida perspectiva representa "uma nova tradição em relação à natureza do letramento, focando não tanto na aquisição de competências, como acontece nas abordagens dominantes, mas sim sobre o que significa pensar letramento como uma prática social". Não obstante a importância desse esclarecimento, seu sentido é mais completo entre os falantes de língua inglesa, devido ao fato de que a mudança de perspectiva não suscitou alteração no termo em si.

Já entre os brasileiros, o conhecimento sobre essa mudança de perspectiva chegou junto com o surgimento de um novo termo (letramento como tradução para literacy), o qual se diferenciaria da noção de alfabetização, palavra que expressava práticas de utilização da escrita que não levavam em consideração os aspectos sociais dessa utilização. Desse modo, como afirma Kleiman (2008, p.489 [grifo da autora]), no Brasil, "todos os estudos do letramento [ainda] são novos", pelo fato de que eles só começaram a ser empreendidos a partir da década de 1990.

Seja como for, importa para nós o fato de Street (2004) destacar a relevância de estudar as questões locais e globais relativas às práticas situadas do letramento, uma vez que este é sempre evidenciado e realizado em práticas locais, sem que, com isso, devamos desconsiderar a sua relação com as questões de natureza global. Em função 
desses aspectos, Street e Lefstein (2007) destacam a relevância dos estudos de caráter etnográfico para os NLS, já que, de acordo com esses autores, uma etnografia do letramento proporcionaria não apenas a compreensão do "como" as práticas de letramento acontecem, mas também do "por que" acontecem e do "que" elas comportam em termos de significação. Desse modo, ainda que seja uma tarefa bastante complexa, é possível identificar as formas culturais de letramentos situados, assim como as estruturas de poder que ali estão presentes.

Nessa mesma perspectiva, Barton e Hamilton (2000, p.8) delineiam proposições a respeito da natureza do letramento, entre as quais merecem destaque o fato de o "letramento ser melhor entendido como um conjunto de práticas sociais, as quais podem ser inferidas de eventos que são mediados por textos escritos". Além disso, ainda de acordo com estes autores, as práticas de letramento são ações historicamente situadas e uniformizadas por relações de poder, as quais estão envolvidas tanto de finalidades sociais mais amplas como de práticas culturais específicas. Ao tomarmos tais proposições como uma das referências para analisar a agência dos estudantes de escola pública, em zonas periféricas da cidade de Fortaleza, percebemos que elas também se alinham aos postulados de Charlot (1997) quando afirma que, para tornar-se um sujeito, ninguém pode escapar da obrigação de aprender, isto é, de se apropriar do mundo e de construir saberes. Nesse processo, sendo o saber o produto de um tipo específico de aprendizagem, que existe somente pela e na linguagem, o letramento, como a capacidade de aprender/saber-fazer bom uso da língua em movimento nas esferas sociais de comunicação, configura-se também como um constituinte da agência humana.

Vale ressaltar, contudo, que, se os agentes são igualmente atores e sujeitos, podemos considerar a agência humana como sendo também a ação de um ser singular, exemplar único da espécie humana, que constrói uma história, interpretando o mundo e a ele atribuindo um sentido, do mesmo modo que significa a posição que ocupa nesse mundo, as suas relações com os outros, a sua própria história e a sua individualidade (CHARLOT, 1997). Nessa perspectiva, e segundo a formulação teórica básica de Charlot, para que um sujeito se envolva em alguma prática ou atividade, ele deve se mobilizar, e para que haja algum tipo de mobilização, a situação a ser vivenciada, ou o saber a ser construído nessa vivência, deve ter algum sentido para ele, ou seja, precisa despertar no sujeito o desejo de se engajar. Assim, se entendermos letramento como sendo também um conjunto de práticas sociais, deduzidas a partir de eventos mediados pela atividade de escrita (BARTON; HAMILTON, 2000), então podemos considerar a agência como uma ação que emerge das práticas de letramento, a partir das quais os sujeitos constroem sentido para guiar sua ação de linguagem.

No que concerne à ação do sujeito, Orlikowski (2000) pondera que este, ao fazer uso da tecnologia, tanto pode reforçar como alterar estruturas institucionalizadas, em consonância com as regras e pressupostos estabelecidos no contexto dessas estruturas, como também fazer usos diferentes daqueles que ali são considerados como legítimos e aceitos. Desse modo, segundo a autora, embora as tecnologias possam congregar características materiais e simbólicas específicas, elas só estabelecem estruturas se forem instanciadas na e pela prática dos indivíduos. Em outros termos, as estruturas tecnológicas não existem sem a ação humana, pois elas se constituem pelo uso e na interação situada, configurando-se como tecnologias em uso (technologies-inpractice). Portanto, o uso das tecnologias digitais presentes na escola pode revelar práticas de letramento bastante criativas por parte dos alunos, ainda que as lógicas da 
estrutura escolar tentem direcionar e policiar esse uso conforme suas regras e normas institucionais.

Isso ocorre devido ao fato de eles serem sujeitos, portadores de desejos que os fazem movimentar-se no interior de estruturas que lhes são preexistentes e que não se reduzem ao aqui e ao agora (CHARLOT, 1997). Assim, em um campo como o sistema escolar, acerca do qual estamos refletindo e onde as práticas de letramento são configuradas também por relações de poder, os estudantes não se encontram sozinhos. Eles se engajam com outros sujeitos em um contexto de ação coletivamente organizado devido ao fato de que a agência é, antes de tudo, um processo dialético e dialógico, dentro do qual os agentes constroem mobilização e sentido para o agir. Desta maneira, devido ao aspecto temporal que envolve a agência (EMIRBAYER; MISCHE, 1998), os sujeitos ajustam suas ações às exigências do contexto condicionante e situacional em que estão imersos, mas também empreendem continuamente alterações nas condições estruturantes desse campo. Nesse processo, eles imprimem, por meio de suas ações, flexibilidade, inventividade e posicionamento crítico acerca dos padrões e repertórios estabelecidos.

Com base no que expusemos acima, podemos concordar com Caetano (2011, p.166) que é na condição de "sujeito que o indivíduo, através de mecanismos singulares de reflexividade, atribui sentido às suas acções, toma por objecto os limites e possibilidades das suas condições e contextos e opta por orientar as suas condutas num determinado sentido, que pode ou não contrariar os seus posicionamentos como agente e como actor". Assim, se letramento, linguagem e cultura estão intimamente enredados, um não pode ser estudado sem o outro, especialmente quando um pesquisador procura compreender um conceito tão complexo como o de agência, haja vista os significados culturais serem, na maioria das vezes, constituídos por meio de práticas de letramento, isto é, de interações verbais (AHEARN, 2001). Se de um lado, como mostra Giddens (1979), as ações das pessoas são moldadas pelas estruturas sociais, do outro essas mesmas ações também servem para reconfigurar as estruturas. Portanto, o sujeito se constitui a partir do social, que lhe é preexistente, mas este não é, como afirma Charlot (1997), o determinante de sua história de vida, de suas ações, especialmente porque o indivíduo se apropria do social em forma de atividades, as quais são socialmente definidas, mas são também atividades de um sujeito que lhe atribui sentido.

\section{REFLEXÕES A PARTIR DA PRODUÇÃO TEXTUAL DOS ALUNOS}

Com fulcro na discussão teórica acima, analisaremos, na sequência, a produção de histórias em quadrinhos como uma significativa prática de letramento (BARTON; HAMILTON, 2000), buscando compreender, nessa atividade, o modo como os estudantes manifestaram sua agência e imprimiram inventividade e posicionamento crítico em suas ações (EMIRBAYER; MISCHE, 1998), a partir das orientações

fornecidas pela professora. Metodologicamente, relacionaremos os significados culturais que se revelam a partir da produção das histórias e as intencionalidades que podem ser flagradas nas explicações dadas pelos sujeitos, durante a entrevista. Para isso, exibiremos os quadrinhos com as histórias produzidas pelos estudantes, analisando não apenas o teor dessas histórias, mas também fazendo associações entre este e as mobilizações que impulsionaram a sua elaboração por meio de recortes das falas, que foram gravadas e posteriormente transcritas. Durante o nosso exercício de análise, duas categorias analíticas emergiram dos dados: 1) as experiências com a ferramenta digital; 
e 2) as "caricaturas" dos estudantes sobre o universo escolar e as lições aprendidas. Na sequência, discutiremos sobre cada uma das categorias de análise.

\subsection{Das experiências com a ferramenta digital}

As tirinhas produzidas pelos alunos incidiram em algo que ultrapassou positivamente os limites do objetivo que orientava a tarefa sugerida pela professora mediadora das oficinas de letramento digital, que era o de aprender a escrever textos multimodais por meio de ferramentas da web. Essa afirmação se justifica porque a orientação do Amplinks era, a priori, que os alunos se dispusessem a aprender o manuseio das ferramentas de edição/criação de tirinhas fornecidas pela Pixton para, por meio desse saber, retratar a realidade de seu cotidiano, como lhes fora solicitado e orientado. Para além disso, os alunos ressignificaram a proposta da atividade e transformaram as histórias em quadrinho em um instrumento semiótico de manifestação de seus modos de compreensão crítica sobre o campo escolar e de elucidação de elementos simultaneamente salientes e desconhecidos da realidade circundante à estrutura desse campo.

Vejamos, pois, o exemplo da tirinha abaixo:

Figura 1 - Explorando as ferramentas de edição/criação para falar do cotidiano

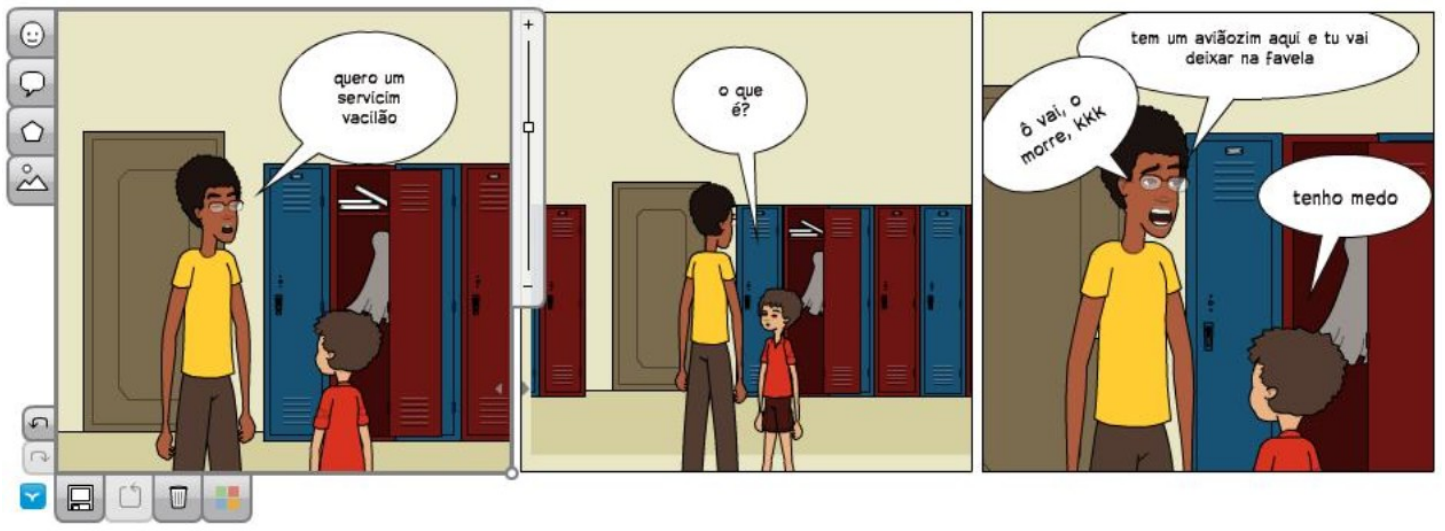

Ao serem entrevistados, perguntamos aos estudantes como foi para eles a atividade de produzir tirinhas na escola por meio de ferramentas digitais. As respostas que obtivemos nos conduziram à identificação de duas dimensões intercambiáveis dessa experiência: uma dimensão técnica e uma dimensão social. No que se refere à dimensão técnica, os relatos dos alunos nos permitem inferir que foi importante aprender o uso da ferramenta Pixton, pois isso auxiliou que eles ampliassem seus letramentos visuais, ultrapassando os limites da tarefa escolar, alertando a escola sobre o cotidiano violento com o qual eles convivem rotineiramente.

Quanto à dimensão social, que perpassa e, ao mesmo tempo, dá contornos ao uso dessa dimensão técnica, a entrevista ratifica o quadro temático que encontramos nos textos dos alunos, por meio dos quais eles também interpelam, indiretamente, a escola a tomar alguma atitude acerca de fatos que são ameaçadores de sua integridade física e social, alguns dos quais, inclusive, ocorrendo dentro do próprio espaço escolar. Portanto, em função do que discutimos sobre a chegada da perspectiva dos "new 
literacy studies" no Brasil (KLEIMAN, 2008), podemos afirmar que a prática de letramento vivenciada por esses estudantes não foi apenas um fato novo que ocorreu em função de ser diferente naquele contexto, pelo uso dos computadores conectados à internet, mas foi, sobretudo, uma ação comunicativa realmente nova devido ao fato de que a mediação oferecida pelas OLDs proporcionou a eles construírem posicionamento social para além da posição de estudantes, uma vez que no Brasil, o ensino da leitura e da escrita no ambiente escolar tem sido tradicionalmente concebido como o contato dos alunos com uma grande quantidade de tarefas obrigatórias e atividades escolares para as quais eles não são capazes de atribuir outro significado senão o de uma obrigação para com a escola.

Para ilustrar essa discussão, disponibilizamos trechos da entrevista no quadro 1, abaixo.

Quadro 1 - O que representou para os estudantes as tarefas de produzir tirinhas na escola

\begin{tabular}{|c|c|}
\hline Dimensão Técnica & Dimensão Social \\
\hline $\begin{array}{l}\text { Aluno } 1 \text { - No meu caso, foi importante } \\
\text { porque ... você cria as próprias } \\
\text { histórias, né? .... (risos) } \\
\text { Aluno } 2 \text { - A importância foi de ter feito } \\
\text { os quadrinhos ... nunca eu tinha feito. } \\
\text { Nunca tinha criado, aí .... Eu criei lá o } \\
\text { quadrinho e foi legal! } \\
\text { Aluno } 3 \text { - Gostei demais de ter feito } \\
\text { mesmo ... de ter escolhido as coisas ... } \\
\text { assim, pra fazer. }\end{array}$ & $\begin{array}{l}\text { Aluno } 1-\text { Eu gostei porque eu contei a } \\
\text { realidade que acontece nas ruas, né? ... } \\
\text { porque eu vejo muito, aí ... eu botei lá no } \\
\text { quadrinho. } \\
\text { Aluno } \mathbf{2} \text { - Porque quando você liga a } \\
\text { televisão, é a primeira coisa que vem é ... } \\
\text { assalto, assassinato... } \\
\text { Aluno } \mathbf{3}-\ldots \text { Porque hoje, os jovens tão } \\
\text { tudo se perdendo nas drogas ... essa questão } \\
\text { ai, desses homicídio, desses assalto ... que } \\
\text { acontece diariamente aqui. }\end{array}$ \\
\hline
\end{tabular}

Conforme afirmamos, os estudantes se engajaram com entusiasmo no projeto, produzindo quadrinhos cujo conteúdo apontava para uma rotina violenta, e indubitavelmente assustadora, em se tratando do cotidiano de uma criança em idade escolar. Neste quadro, dois aspectos importantes nos chamaram a atenção. O primeiro deles diz respeito ao manuseio pelos alunos dos botões de edição/criação das tirinhas, pois expressões como "cria as histórias", "gostei de ter escolhido as coisas" sinalizam para o trabalho de navegação/composição dos textos multimodais. Se observarmos a figura 1, acima, veremos que, no lado lateral esquerdo da tirinha, estão disponíveis botões que permitem, respectivamente, adicionar personagem, adicionar balão, adicionar forma, adicionar fundo, adicionar imagem, além de botões que permitem nulificar o texto, reformulando-o. Na parte inferior da figura, outra barra de ferramentas oferece botões que permitem novas ações de edição, como adicionar uma cena, salvar uma cena, eliminar uma cena, salvar cenário, entre outras possibilidades. Produzir uma tirinha, portanto, para os alunos, implicou inicialmente aprender a navegar pela ferramenta, extraindo dela possibilidades multimodais para expressar, da melhor forma possível, o conteúdo escolhido para história, já que os estudantes participantes do Amplinks sempre têm a oportunidade de produzir várias versões de uma única tirinha.

O segundo aspecto incide na insistência do verbo "criar" que aparece nas falas dos informantes. Dominar a tecnologia foi importante para que os sujeitos 
aproveitassem a cena pedagógica para protagonizar cenas de letramento crítico na medida em que, por saberem criar suas tirinhas, tinham a conveniência de evidenciar nelas o seu cotidiano. Expressões como "contei a realidade que acontece nas ruas", "eu botei lá no quadrinho" ou ainda "Gostei ... de fazer" propalam o posicionamento crítico dos estudantes em relação às orientações fornecidas pela professora e às normas que orientam e configuram habitualmente as práticas escolares. Nesse processo, os estudantes não perderam de vista os limites de sua condição de aluno, mas também, por serem sujeitos, não se omitiram de ir além das normas e regularidades que contornam as tarefas escolares, atribuindo outro sentido a sua relação com as atividades de leitura e escrita.

Com isso, os alunos realizaram modificações na estrutura institucionalizada na escola e que orienta tais atividades, empregando o que Orlikowski (2000) chama de technologies-in-practice. Nessa perspectiva, podemos afirmar que não foi o computador ou mesmo o software usado que engatilhou essa agência dos alunos, mas o fato de o Amplinks, por meio das OLDs, proporcionar um contexto de letramento diferente daquele que é fomentado pelas políticas oficiais brasileiras de inclusão da informática na escola, as quais são voltadas, com raras exceções, muito mais para a capacitação no uso das ferramentas do que para a educação linguística via technologies-in-practice (ARAÚJO; SANTOS, 2012; 2014). Portanto, podemos dizer que eles perceberam "como fazer coisas com as palavras" (AUSTIN, 1962), na medida em que, escrever historinhas em quadrinhos implicou, por meio das palavras e das imagens disponibilizadas pela tecnologia digital, fazerem suas vozes ecoarem pelos corredores da escola e denunciarem a realidade violenta na qual vivem e da qual estão cansados.

Como dissemos, há alguns parágrafos atrás, a escola a que nos referimos neste texto oferta para a comunidade em que está inserida a educação infantil e o fundamental, logo, no mesmo espaço convivem crianças pequenas e adolescentes. Assim, se o leitor voltar a observar a tirinha 1, perceberá dois personagens: um adolescente e uma criança. No supracitado quadrinho, notará que a criança é abordada pelo personagem adolescente que a obriga trabalhar no tráfico, já que, após a aula, a criança deverá entregar droga em uma determinada favela, sob pena de ser morta. $\mathrm{O}$ medo, portanto, é uma realidade no cotidiano desses indivíduos, devendo ser por eles sublimado porque são, desde cedo e sob ameaças, obrigados à inserção em uma teia perigosa de tráficos de drogas.

Durante a entrevista, voltamos ao que retrata o texto da figura 1 , conforme trechos exibidos no quadro 2, abaixo:

Quadro 2 - Explicação sobre o conteúdo temático das histórias

\begin{tabular}{ll}
\hline \multicolumn{1}{c}{ Perguntas } & $\begin{array}{l}\text { Aluno 1 }-\ldots \text { já tive muitas propostas de } \\
\text { entorpecentes, mas, eu num }\end{array}$ \\
$\begin{array}{l}\text { Pesquisadores }-\mathrm{E} \text { vocês já foram } \\
\text { obrigados a fazer algo como o que aparece } \\
\text { nas histórias de vocês? }\end{array}$ & $\begin{array}{l}\text { aceitei não. Mas, já tive muitas propostas } \\
\text { já. }\end{array}$ \\
$\begin{array}{l}\text { Pesquisadores - Aquilo que aparece nos } \\
\text { quadrinhos, então, é uma realidade de } \\
\text { vocês? }\end{array}$ & $\begin{array}{l}\text { Aluno 2 - Na própria sala, na própria sala } \\
\text { cheiradinha aqui e tal! ... pega maconha, } \\
\text { tem uns pacotes de maconha, ... Ai eu }\end{array}$ \\
\hline
\end{tabular}


disse: - não, não, quero não, valeu! É, $\operatorname{assim} . .$. e se você for fraco, cai na primeira!

As entrevistas confirmam que há uma relação entre as tirinhas e a realidade dos informantes. Ao se apropriarem das habilidades de navegação e dos recursos oferecidos pela Pixton, os estudantes se esforçam para deixar uma importante sinalização de que a escola pode não ser apenas um local de ensino, mas se configurar também, sob a ótica dos alunos, como um cenário de ações clandestinas, das quais ela talvez nem tome conhecimento. Portanto, a agência contida nessa prática de letramento, desempenhada pelos estudantes, instala uma relação direta com suas histórias singulares (CHARLOT, 1997), mas, principalmente, com suas experiências sociais de partilhar as mesmas condições de vida (ARCHER, 2003).

Chama-nos a atenção o fato de que, mesmo dentro da sala de aula, sob a suposta segurança dos muros da escola, os estudantes são assediados por pessoas que se infiltram na instituição a fim de, com violência e ameaças, recrutar crianças para o tráfico de drogas. As falas dos estudantes 1 e 2 mostram o esforço que eles impetram para sair incólumes dos assédios que sofrem sob a soleira da escola. Em função disso, procuramos saber qual a audiência que esses escritores pretendiam alcançar com a produção de suas tirinhas, haja vista as práticas de letramento estarem sempre imbuídas de intencionalidade, vinculando-se a objetivos sociais mais amplos e a práticas culturais, como defendem Barton e Hamilton (2000).

O quadro 3, abaixo, ilustra trechos da entrevista em que abordamos essa questão.

Quadro 3 - O sentido atribuído à produção das tirinhas

Perguntas Respostas

Aluno 1 - No caso a gente queria

Pesquisadores - E pra quem vocês repassar o que acontece no dia-a-dia para estavam escrevendo os quadrinhos? a professora e para a escola.

Pesquisadores - Então, vocês queriam Aluno 2 - Eu acho que os professores mostrar para os professores?

Pesquisadores - E vocês conversam sobre isso com os seus professores? escutam falar, mas não presenciam o que nós sofremos.

Aluno 3 - É como se fosse assim ... é que a gente pensa que eles não vão dar ouvidos, porque ... num vão conseguir entender o que a gente quer repassar para eles. As nossas tirinhas é como se fosse uma indireta, né?

Os estudantes acentuam a informação de que, uma vez se apropriando das ferramentas digitais de escrita multimodal das tirinhas, eles aproveitariam a 
conveniência para mobilizar esse saber (CHARLOT, 1997) em prol da intenção de denunciar o seu cotidiano à escola. Tanto as tirinhas que coletamos quanto as entrevistas realizadas com seus autores deixam entrever uma crítica à escola por não ter construído a prática de escutar os alunos e, por isso, desconhecer muitas coisas sobre eles. Julgamos ser esse um dado muito importante porque vislumbramos que a agência se traduz nos letramentos críticos dos atores em moldar a sua capacidade de dar respostas a situações problemáticas que vivenciam em meio a estrutura que os circunda (EMIRBAYER; MISCHE, 1998). Assim, ao usarem a tecnologia a seu favor, os estudantes não apenas produzem as tirinhas, mas ingressam em um processo (re)criador de sua realidade, ao mesmo tempo em que se utilizam deste raciocínio para exercer o controle e antecipar suas respostas a um porvir que pode lhes soar como uma ameaça.

Intuímos que os significados culturais que se revelam a partir da produção dos quadrinhos desses estudantes apontam, infelizmente, para uma cultura de violência, de crime e de morte da qual os atores em tela procuram fugir e, por isso, suas tirinhas podem ser interpretadas como pedidos de socorro. A estratégia dos estudantes, portanto, funcionou na medida em que a atividade de escrita multimodal das tirinhas teve impacto não apenas em suas vidas como também na escola, que acolheu os resultados desse trabalho como um ensejo para desenvolver ações que pudessem proteger essas crianças e adolescentes, de certo modo, bastante vulneráveis às situações de risco aludidas. No entanto, é preciso ressaltar que, resguardadas as devidas interpretações, não estamos diante de crianças e adolescentes ingênuos e pueris que desistiram de si e/ou que não lutam em favor de seus objetivos, afinal, na condição de sujeitos, impregnam de intenções a estrutura do campo escolar onde circulam (ORTNER, 1996), conforme mostraremos a seguir.

\subsection{Das "caricaturas" dos estudantes sobre o universo escolar e as lições aprendidas}

O fato de se apropriarem da tarefa da escola e de fazerem dela uma estratégia de autodefesa mostra claramente a capacidade desses sujeitos para formular com criticidade o seu posicionamento sobre a condição em que se encontra a escola frente aos fatos retratados nas tirinhas. Paralelamente, os quadrinhos também exibem representações de elementos relativos a essa instituição, conforme podemos vislumbrar na figura 2, abaixo.

Figura 2 - Representações ligadas ao universo escolar

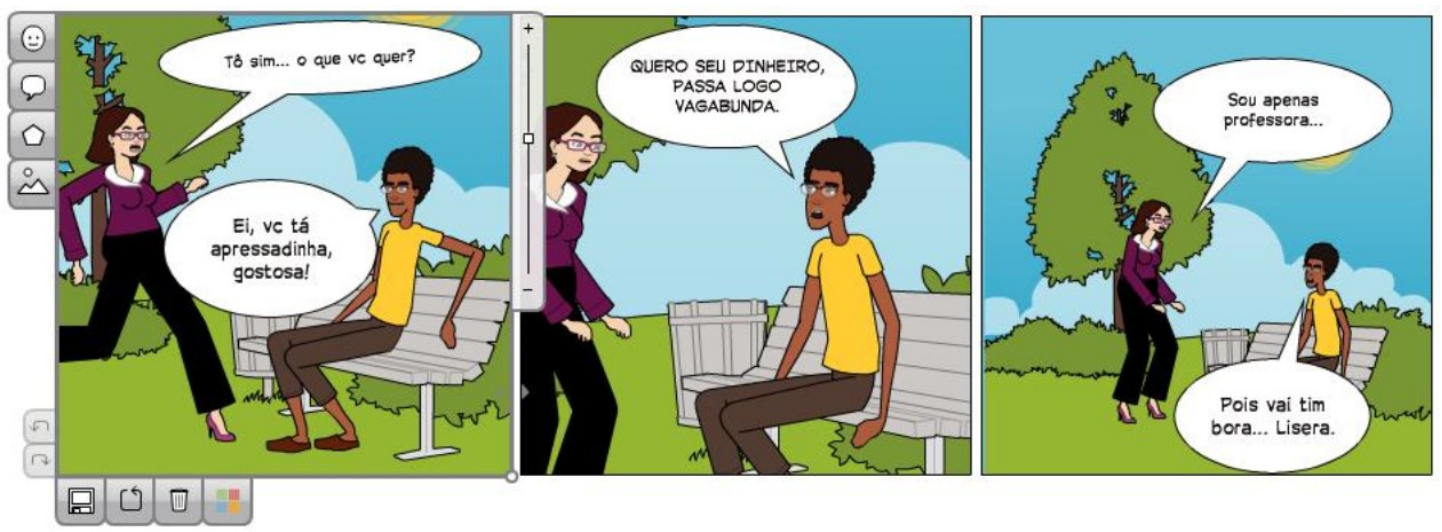


Essa tirinha nos permite inferir que os alunos desconfiam das promessas da escola segundo as quais: "quem estuda vence na vida". Os personagens em cena são um suposto assaltante e uma professora. Afigura-se relevante destacar que o personagem que representa o assaltante é um jovem adolescente e, por isso, encontra-se na mesma média de idade escolar dos informantes desta pesquisa. Julgamos positivo o fato de o autor desse texto não ter trazido para o quadrinho a figura da arma de fogo, o que demonstra, portanto, que eles não são os bandidos, mas as vítimas que pedem socorro.

Por outro lado, o exemplo da personagem da professora inserida nessa tirinha repercute, entre outras coisas, uma representação social segundo a qual o profissional docente é um ser desprovido de prestígio social. Por ter uma péssima remuneração salarial, ele é digno de pena até dos assaltantes que desistem de atacá-lo. Isso pode ser deduzido do significado que a palavra "lisera" (uma gíria cearense para se referir a uma pessoa sem dinheiro), usada para se referir à professora, possui no contexto social dos autores das tirinhas, visto que nesse contexto ser professor implica padecer pela falta de dinheiro e, não ter dinheiro, fato com o qual os estudantes e suas famílias se identificam profundamente, constitui-se motivo de desprestígio social. Portanto, é possível compreender que a "indireta para a escola", acerca da qual o aluno 3 se refere no quadro 3, enfatiza uma vulnerabilidade comum a alunos e professores como tentativa de enfraquecer as relações de poder entre ambos, visto que são os personagens das tirinhas que fazem tais afirmações e não os seus autores.

Vinculada à representação de professor, podemos ainda inferir a noção de que estudar é um investimento que não vale a pena e, por isso, frases como: "estude para ser gente" ou ainda: "estude para ter um emprego no futuro" já não são aceitas como um fatalismo positivo. As promessas da escola não mais ressoam como esperança entre os estudantes, os quais cogitam que a experiência escolar de sua infância e juventude, no presente, não é uma garantia de que eles não serão alcançados pelo mundo do crime e da violência. Os informantes expõem sua condição de vulnerabilidade com franqueza e, ao fazê-lo, exibem as feridas de um estado falido que abandona, à mercê da própria sorte, jovens, escolas e famílias, especialmente as de bairros menos favorecidos.

Apesar de tudo isso, as falas dos estudantes revelam que as oficinas de letramento digital podem ter tido algum impacto positivo em suas vidas na medida em que, segundo os trechos da entrevista no quadro 4, abaixo, eles refletem sobre um falso poder que pode lhes arruinar a vida, caso optem pelo uso de armas de fogo.

Quadro 4 - O saldo positivo das oficinas

\begin{tabular}{ll}
\hline \multicolumn{1}{c}{ Perguntas } & \multicolumn{1}{c}{ Respostas } \\
$\begin{array}{l}\text { Pesquisadores - O que vocês acham que } \\
\text { mudou em vocês durante e depois das } \\
\text { oficinas? }\end{array}$ & $\begin{array}{l}\text { Aluno } \mathbf{1} \text { - Rapaz, a gente é muito } \\
\text { pensava que chegar com a arma na mão, } \\
\text { né?... isso era poder. Mas, isso é só } \\
\text { muito influência. }\end{array}$ \\
Pesquisadores - E o que mudou? & $\begin{array}{l}\text { Aluno } \mathbf{2}-\text { Eu vi que isso não leva a } \\
\text { nada, não. Você pode tá com o poder da } \\
\text { arma na mão, você se sente um "bichão", } \\
\text { manda no pedaço, mas, na verdade, não é }\end{array}$ \\
\hline
\end{tabular}


não. Ali é só ... passageiro. Se for pego, acaba o poder, além de passar por toda a humilhação.

Pesquisadores - E qual foi o resultado dessas histórias? Vocês acham que foram ouvidos? Conseguiram isso?
Aluno 3 - Eu vi que nada disso aí não leva a nada não. Depois, vai pra cadeia, se arrepende, pronto, passou. E depois que passou pela cadeia, pra arrumar um emprego, pra voltar a sociedade é super difícil.

Aluno 1 - Acho que conseguimos, né? ... nós tamo aqui, né? (falando sobre o tema).

Como podemos perceber, as palavras "humilhação", "passageiro", "cadeia" e "emprego" emergem de suas falas denotando o desejo de continuarem inseridos na sociedade e parecem ratificar a intenção de fugirem de um futuro no qual não sejam pessoas produtivas ou tão desprestigiadas quanto os adultos com os quais partilham o mundo.

\section{CONSIDERAÇÕES FINAIS}

Em função da paisagem teórica exposta neste artigo e, sobretudo, dos dados que emergiram das oficinas de letramento digital nas escolas contempladas pelo nosso programa de extensão Amplinks, podemos afirmar que os alunos, partícipes dessas oficinas, conseguiram romper com a estrutura escolar e, assim, posicionar-se mais livremente por meio das tirinhas por eles produzidas. Os dados analisados ainda nos permitem dizer que, mesmo sem usar a linguagem canônica ensinada e celebrada pela escola, esses estudantes se apropriam de tarefas escolares para questionarem o poder daquela instituição, e suas promessas de emancipação, devido, especialmente, ao abandono que ela sofre por parte de algumas das políticas educacionais promovidas pelo estado brasileiro.

Para além do domínio de competências para lidar com ferramentas digitais na escola, e mais do que o simples domínio de um gênero textual trabalhado nas oficinas, os quadrinhos produzidos pelos alunos revelam sua agência na medida em que eles, com argúcia, percebem que não haveria outro modo de se fazer notar e ouvir pela e na escola se não fosse por sua capacidade de se apropriar das atividades escolares de escrita para publicar sua voz e seu posicionamento frente à realidade social em que estão inseridos. Desse modo, o programa de extensão Amplinks propiciou aos alunos uma oportunidade de romperem com a "passividade" suposta pela tarefa e levantarem questionamentos sobre e para o sistema escolar. Portanto, à medida que aprendiam a escrever suas tirinhas, eles dialogaram com a escola através de uma provocação cuja finalidade foi a de promover discussões sobre temas que são considerados por eles como conteúdos ausentes na prática pedagógica daquela estrutura institucional.

Com isso, os professores deixam de ser os únicos que ocupam o lugar de proponentes de atividades no campo escolar, sendo relevante notar que as narrativas incorporam dados relativos a todos os sujeitos que atuam nesse campo. Os estudantes, 
livrando-se do medo dos erros ortográficos e da aparente rejeição dos professores ao tema tratado, colocam falas na boca de personagens que, na verdade, são suas. Essas falas são deslocadas projetivamente para não serem ignoradas ou reprimidas. Assim, mesmo que tenha sido uma professora a propor a atividade, mas foram os alunos que conduziram os temas, conforme seus interesses. Esses temas são de interesse do coletivo dos alunos e, portanto, inspiram a produção dos textos (tirinhas) imbuída de um intenso significado social para eles.

\section{REFERÊNCIAS}

AHEARN, Laura M. Language and Agency. Annual Review of Anthropology, 30, p. 109-137, 2001.

ARAÚJO, Júlio. O texto em ambientes digitais. In. COSCARELLI, Carla V. Leituras sobre a leitura: passos e espaços na sala de aula. Belo Horizonte: Vereda, 2013, p. 88115.

ARAÚJO, Júlio; SANTOS, Leonel Andrade dos. Histórias em quadrinhos digitais: ampliando os links com os letramentos e sintaxe visuais na escola. In: CARVALHO, Diógenes Buenos Aires de; et al. (Org.). Linguagens, cultura e ensino. Jundiaí-SP: Paco Editorial, 2014, p. 73-89.

ARAÚJO, Júlio; SANTOS, Leonel Andrade dos. A ferramenta digital máquina de quadrinhos em uma experiência didática com letramento visual.. In: RIBEIRO, Ana Elisa; NOVAIS, Ana Elisa. (Org.). Letramento digital em 15 cliques. Belo Horizonte: RHJ, 2012, v. 1, p. 45-57.

ARCHER, Margaret S. Structure, Agency and the Internal Conversation. Cambridge: Cambridge University Press, 2003.

AUSTIN, John L. How to do things with words. London: Oxford University Press, 1962.

BARTON, David; HAMILTON, Mary. Literacy practices. In. BARTON, David; HAMILTON, Mary; IVANIČ, Roz. Situated literacies. London: Routledge, 2000, p. 715.

BOURDIEU, Pierre; WACQUANT, Loïc. An Invitation to Reflexive Sociology. Cambridge, MA: Polity Press, 1992.

BRASIL. Lei de Diretrizes e Bases da Educação Nacional. Lei n. ${ }^{\circ}$ 9.394/96, de 20 de dezembro de 1996.

CAETANO, Ana. Para uma análise sociológica da reflexividade individual. Sociologia, Problemas e Práticas [online]. n.66, p. 157-174, 2011.

CHARLOT, Bernard. Du rapport au savoir : éléments pour une théorie. Paris: Anthropos, 1997. 
CHARLOT, Bernard. A mobilização no exercício da profissão docente. Transcrição da Palestra de Abertura do I Colóquio Internacional de Formação Inicial e Continuada de Professores de Línguas Estrangeiras, proferida em 16 de março de 2012. Revista Contemporânea de Educação, n.13 - Jan./jul. 2012.

DIEB, Messias. A leitura na sala de aula. In. COSCARELLI, Carla V. Leituras sobre a leitura: passos e espaços na sala de aula. Belo Horizonte: Vereda, 2013, p.36-59.

EMIRBAYER, M.; MISCHE, A. What is agency? American Journal of Sociology 103(4), p. 962-1023, 1998.

GEE, James. Social Linguistics and literacies: ideology in discourse. London: The Falmer Press, 1990.

GIDDENS, A. Central problems in social theory. New York, NY: Macmillan, 1979.

KLEIMAN, Angela B. Os estudos de letramento e a formação do professor de língua materna. Linguagem em (Dis)curso - LemD, v.8, n.3, p.487-517, set./dez. 2008.

MONLEVADE, João. Educação pública no Brasil: contos e descontos. Ceilândia - DF: Idea Editora, 1997.

ORLIKOWSKI, Wanda. Using Technology and Constituting Structures: A Practice Lens for Studying Technology in Organizations. Organization Science, v.11, n.4., p. 404-428, 2000.

ORTNER, Sherry B. Making gender: the politics and erotics of culture. Boston, MA: Beacon Press, 1996.

STREET, Brian; LEFSTEIN, Adam. Literacy an advanced resource book for student. Canada: Routledge, 2007.

STREET, Brian. Futures of the ethnography of literacy? Language and Education. King's College, London, UK. v.18. n.4, p.326-330, 2004.

STREET, Brian. Literacy in theory and practice. Cambridge: CUP, 1984.

STREET, Brian. Literacy practices and literacy myths. In: SALJO, R. (Ed.) The written world: studies in literate thought and action Springer-Verlag: Berlim/Nova Iorque, 1988, p.59-72.

STREET, Brian. Social literacies: critical approaches to literacy in development: ethnographic perspectives. Londres \& New York: Longman, 1995.

STREET, Brian. What's "new" in New Literacy Studies? Critical approaches to literacy in theory and practice. Current Issues in Comparative Education. Teachers College, Columbia University. v,5(2), p.77-91, 2003. 
Recebido em: 17 de fevereiro de 2014.

Aceito em: 20 de maio de 2014 . 